\title{
DEVELOPMENT OF A PERSONAL INFORMATION SYSTEM FOR MANAGING AUDIOVISUAL TRAINING AIDS: MOTIVATIONS, BENEFITS FOR THE TEACHER'S WORK
}

\author{
T. Georgieva-Trifonova ${ }^{1 *}$, S. Lazarova ${ }^{2}$ \\ ${ }^{1}$ Faculty of Mathematics and Informatics, "St. Cyril and St. Methodius" University of Veliko Tarnovo, \\ Bulgaria \\ ${ }^{2}$ Faculty of Pedagogy, "St. Cyril and St. Methodius" University of Veliko Tarnovo, Bulgaria

\begin{abstract}
The contemporary teacher uses a rich collection of diverse computer-based teaching aids in their daily experience. One of the main problems in his work is maintaining this collection so that in case of need a desired file can be found quickly and reliably. In this paper, an approach to systematizing, organizing, storing and using the audiovisual aids with the personal information system myAudiovisualAids is proposed. The purpose of the implemented system is to support the user to organize his/her media learning resources created during the preparation of the lessons or his/her library of digital didactic aids. The motivations are justified and the benefits of developing and using the proposed system are addressed.
\end{abstract}

Keywords: audiovisual aids, personal information system, electronic library, teacher's work

\section{INTRODUCTION}

Experience shows that the contemporary teacher uses audiovisual aids in their daily professional work. These days there is a wide variety of digital resources.

In the age of internet compatible mobile technology most people have access to information anytime and anywhere thanks to the easy-to-use mobile devices. The whole information is at arm's length using tablets and phones with active internet connection. This development in technology has a huge impact on education. Whether we like it or not, technology has already affected the way we study: the learning strategies have altered. If student $X$ is totally unaware of a given topic, he just has to search for it online (1). In this information chaos teachers constantly have to create, update, add, search aids to illustrate the educational content while considering every student's personal style of learning. One of the

"Correspondence to: Tsvetanka GeorgievaTrifonova, "St. Cyril and St. Methodius" University of Veliko Tarnovo, Faculty of Mathematics and Informatics, 3 Arch. Georgi Kozarev, 5000 Veliko Tarnovo, Bulgaria,email: cv.georgieva@uni-vt.bg main problems contemporary teachers encounter is organizing and finding the audiovisual aids they have already created and used.

In this regard, there is an intensive evolution of two categories of information systems - school information systems and learning management systems. Undoubtedly, each of these weighty software products provides enormous possibilities. The point is how this software can be used easily for solving the most frequently performed tasks, related to the work of a teacher who plans, creates and applies digital learning resources while conducting lessons in a traditional learning environment. The purpose of the presented system myAudiovisualAids is different: easy manipulation with those digital didactical aids (lessons, presentations, etc.) and data about them which is used many times and is needed at every step of their teaching work; providing quick and intuitive access to the personal media learning resources in preparation of the lessons.

More concretely, the implemented system can be utilized for the following: 
- Systematization and organization of the audiovisual aids;

- Storage and retrieval by criteria set by the teacher (topic, section, course, type of lesson, date, file format, etc.);

- Quick search by keywords and/or categories;

- Updating the media learning resources.

An essential feature of the information system myAudiovisualAids is that it must be able to be developed and modified by the teacher himself, i.e. its creation and the addition of new functionalities should not require professional competencies in the field of informatics and engineering. The details related to the design and the implementations of myAudiovisualAids, described in this paper, and are intended to confirm that this requirement is realistic.

Apart from that, the aforementioned system is used to teach students in Masters programs, who work or are yet to work as teachers (for now in the primary education), in order to help them acquire skills for:

- Creating other similar applications on their own, which will be helpful in their work;

Examples for such applications are the ones used for maintaining the coursework, test containing information for typical mistakes, results, etc. This information allows extracting summaries by years in order to compare, analyze, etc.

- Modifying the system, so that it corresponds with their specific requirements and needs.

In addition to the acquired skills, students increase their motivation for learning the concepts connected with information systems and their development because they succeed to realize their advantage while working. As a result, there is an increase in students' interest in making the needed effort to obtain the theoretical and practical competences. It is important to note that students in the role of teachers, using information system, created or further developed by them, would contribute to the respect and the motivation of their learners. Doubtless, a significant part of our motivation for designing and developing the personal information system myAudiovisualAids stems from the study of the following aspects of audiovisual learning aids, discussed in more detail in the following sections of this paper:
- Whether the audiovisual aids have a historical background or they are just a modern trend that will quickly pass away;

- Nowadays, what do we mean by audiovisual learning aid, i.e. what to store in the developed personal information system;

- How can audiovisual learning aids are applied in the classroom to support traditional training.

The rest of this paper is organized as follows. In section 2, different definitions of the concept "audiovisual learning aid" are reviewed in which the authors emphasize on certain aspects and give a summarized definition of this concept. Furthermore, the grounds of using audiovisual aids in the modern classroom are studied. In section 3, authors consider possibilities of applying information systems in schools and justify the motivation for developing an information system which manages the audiovisual learning aids. Section 4 is dedicated to the information system, suggested in this paper, presented are details, connected with its implementation.

\section{ESSENCE AND DEVELOPMENT OF THE AUDIOVISUAL LEARNING AIDS} learning aid"

1. Defining the concept "audiovisual The contemporary teacher uses a wide variety of computer based methods and learning aids in their daily teaching experience. The learning aids increase students' learning interest and motivation and makes explaining concepts easier for teachers (2). Utilizing learning aids objects and processes, which cannot be shown in the school environment, are visualized in the classroom.

According to (3) audiovisual education the using of the supplementary teaching aids such as recordings, transcripts, and tapes; motion pictures and video tapes; radio and television; and computers, is to improve learning.

Every device which via sound and sight increases the individual experience of every student can be called audiovisual aid. Audiovisual aids are those learning aids which are used in the classroom with the aim of encouraging studying and making it easier and more interesting. Materials like film, models, charts, maps, television, etc. are called instructional aids (2). We accept the following 
definition: audiovisual aids in the contemporary education are all digital technology in the classroom (and outside it) which the teacher uses with the aim of increasing learning efficiency.

\section{Audiovisual aid in the contemporary classroom}

Surveys prove the use of audiovisual aids in the classroom helps students understand complex conceptions (4). The latest technological achievements give teachers many opportunities which make their work easier. It is mainly due to this reason that teachers all around the world integrate audiovisual aids when planning their lessons. Audiovisual aids are made to help teachers achieve their pedagogical aims. Overusing technology or using it incorrectly can lead to auditory and visual fatigue amongst students. Therefore, this could have a detrimental impact on the learning process.

Audiovisual aids are used in the classroom in order to encourage teaching and learning. They provide students with realistic experience which lures their attention and makes learning concepts easier; engaged are students' senses hearing and sight, thinking and understanding are being stimulated (2).

Using media in the classroom has its reasons. Some of the more important are (5):

- considering the role of media outside the classroom, students expect a mediaequipped classroom as well;

- media materials make the classroom situation authentic, enhance the direct connection among students in the classroom and the outside world;

- as students have diverse learning styles, media provides us with a way of meeting the needs to both visual and auditory learners.

\section{APPLICATION OF INFORMATION SYSTEMS IN SCHOOLS}

According to some researchers there are two main categories when it comes to using information and communication technology in education: using the technology in class and supporting use of technology (6):

- Firstly, utilizing information and communication technology in the classroom aims to support and assist learning. For example, using computers for demonstration purposes, practical activities, modeling, discussions, collaboration, project work, etc.

- Second category, supporting the use of the information and communication technology, is connected with teachers' administrative duties, such as administration of student's state, preparation of worksheets, assignment activities, saving students' progress, etc.

In recent years, there is a significant increase of arguments which support the idea of using information technology as an instrument for education management and improve the ways to solve tasks connected with the management.

Since the late 1990s, systems for supporting the management of the learning process (Learning Management Systems - LMS) have emerged and actively developed. According to the definition given in (7), an LMS provides the virtual platform for e-learning by enabling the management, monitoring student, delivery, tracking of learning, testing, communication, registration process and scheduling. There are many LMS systems on the market, one part of them are open source software that can be obtained for free (e.g. Moodle, Claroline, A Tutor, etc.); others are commercial software (e.g. Blackboard, WebCT, etc.). Lists and comparative characteristics of such systems are presented in $(8,9)$.

Modern digital technologies are continuously offering increased learning opportunities and expanding the traditional learning environment, which leads to the need from refinement of the organization of audiovisual teaching aids used in teaching. Some of the most significant pedagogical features of learning management systems (10) and the proposed personal information system myAudiovisualAids are presented in Table 1.

The implementation of the personal information system is an extremely creative task, which provides undoubtedly better conditions for enriching the teacher's work; increasing the motivation to apply modern computer-based methods and tools for stimulating the students' activity in a traditional learning environment; ensuring quality and efficiency in educational activities; and achieving teacher's personal satisfaction from the professional interactions. The present research has a definite contribution from a pedagogical point of view to the application of audiovisual technologies in a traditional learning environment. 
Table 1. Comparison of LMS and the personal information system myAudiovisualAids

\begin{tabular}{|c|c|}
\hline Learning management systems & Personal information system myAudiovisualAids \\
\hline Designed for e-learning & Designed for use in traditional teaching \\
\hline $\begin{array}{l}\text { Their implementation is the result of a skilled work of } \\
\text { a team of specialists in the field of informatics and } \\
\text { engineering sciences. }\end{array}$ & $\begin{array}{l}\text { Its implementation and addition of new functionalities } \\
\text { should not require professional competencies in the } \\
\text { field of informatics and engineering. It should provide } \\
\text { a quick and intuitive access to the personal media } \\
\text { learning resources in preparation of the lessons. }\end{array}$ \\
\hline $\begin{array}{l}\text { Part of them is expensive. } \\
\text { The staff should be trained to work with them. }\end{array}$ & $\begin{array}{l}\text { It can be developed by the teacher who must have } \\
\text { digital competence at an unprofessional level. }\end{array}$ \\
\hline $\begin{array}{l}\text { They are unified. Each school is different and has } \\
\text { different information needs. Learning management } \\
\text { systems can meet most of the school needs, but not all. }\end{array}$ & $\begin{array}{l}\text { It meets the personal style of teaching the user, and } \\
\text { that will create conditions for better teaching. }\end{array}$ \\
\hline They require a high-speed internet connection. & $\begin{array}{l}\text { It can work offline. Most of the activities of planning } \\
\text { and conducting training in a traditional learning } \\
\text { environment do not require online connectivity. }\end{array}$ \\
\hline $\begin{array}{l}\text { They are not popular in Bulgarian schools. Their } \\
\text { usage requires a common vision and planning of } \\
\text { school leaderships. }\end{array}$ & $\begin{array}{l}\text { Each teacher can create and apply in the training } \\
\text { personally and independently of other users. }\end{array}$ \\
\hline $\begin{array}{l}\text { It is proposed to use a learning system from different } \\
\text { users with different access - learners, teachers, course } \\
\text { authors, system administrators. }\end{array}$ & The system is used only by the teacher. \\
\hline
\end{tabular}

The information systems are successfully used in teaching, as some of them are utilized in elearning. In synchronous communication the teacher should be agile and able to rapidly find digital audiovisual resources and integrate them in his work immediately. It would be useful if these educational aids are systematized in a database, which could be easily updated.

\section{DESIGNING AND IMPLEMENTING AN INFORMATION SYSTEM FOR MANAGING AUDIOVISUAL \\ TEACHING AIDS}

Necessity. One of the positive sides of digital technology is the ability to reuse learning materials. Lessons and resources, developed in digital format can be saved and archived for later use, which can be helpful in a variety situation. Let's take a look at the following examples:

- A sequence of lessons which are studied every year. In order to save lessons it should be developed in a way that allows its multiple-time use. Even though the core of the lesson may remain mainly the same, some of the content should be updated annually. Reusing the lessons, even by just one teachers saves a lot of time (11);
- $\quad$ Digital lessons can be developed by a group of teachers. In reality, the online collaborative tools are an amazing way for teachers to work together on expanding the main ideas in a lesson or in a whole unit. It is vital that lessons are developed by a group of teachers so as to encourage collaboration, team work and opinion sharing (12);

- $\quad$ Most teachers are reasonably organized. The majority prepares their lessons and creates helpful resources and activities for their students, hoping those lessons will be interesting and engaging. They enter the classroom completely ready and willing to teach their knowledge to students. The main problem, however, is that the 21-st century education does not work that way. Teaching is no longer passing a given set of knowledge to passive students. Teacher's role is changing; his efforts are focused on motiving students to study and research ideas. Sometimes what students should study is not what the teacher initially intended to teach them. The teacher of the 21-st century should be flexible and willing to take cases of deviation in unprepared areas. These deviations are sometimes more valuable 
GEORGIEVA-TRIFONOVA T., et al.

than the lesson itself. Actually, the more teachers use the new digital technology and the more experienced they become the more flexible the transition between the lesson and an interesting "diversion" will be. At the end of the class they will finish with the previously planned lesson.

- Students frequently ask interesting questions. Namely these deviations, arising from unexpectedly asked questions, can be the most interesting, fun and valuable part of the lesson. What is very oppressive about the traditional school is the common situation when students are truly interested or curious to learn something but the teacher is unwilling to devote time to search upon the question and explain it. If we accept that there is real education only when students are occupied with topics they are interested in, then the teacher should take some time to make this important unplanned deviation.

- $\quad$ Contemporary digital technology (such as tablets, interactive whiteboard with internet connection, etc.) is a powerful instrument for making those deviations from the initial purpose of the planned lesson. The possibility of flexible lessons re-routing "on-the-go", for instance to check a digital resource, to find the needed information or data, to have access to a given video or photos, and then go back to the planned lesson can make miracles when it comes to satisfying students' curiosity. Flexibility can be created in one exceptionally powerful, engaging and motivating learning medium, the realization of which is impossible without an information system which systematizes the data.

- Lack of an information system, which helps teachers to use audiovisual aids in their pedagogical experience. A review on the scientific literature was made, followed by an analysis, which both show that there is no such system described. Taking into consideration the rising digital competences of contemporary teachers we do not exclude the probability of such systems to exist, however, just for private use. All those aforementioned facts do not decrease the need to implement the system - on the contrary, it once again draws attention on the topicality of the current study, mostly when it comes to highlighting the basic rules and requirements to design an information system, which will provide its successful implementation.

Main task of the information system for managing audiovisual aids

The software for digital didactic aids is used for organization and systematization of the audiovisual educational aids from teacher's personal computer. Through catalogue or keyword one can search by class, school subject, unit, new knowledge, exercises, verification and assessment of knowledge, file format, etc.

Implementation of the information system for managing audiovisual educational aids

The information system myAudiovisualAids is free and easy-to-use system for managing a database using audiovisual educational aids. This program supports the user to organize their collection of digital didactical aids.

The defined main requirements, considering the functionality of the system, are illustrated in Figure 1 with UML use case diagram of the given system. Main participant is the teacher.

In the conceptual design of the myAudiovisualAids database entityrelationship model is used, introduced in (13). The following entities are established (Figure 2) - Topic, Types, Sections, Courses, Keywords, Classes. The relationships are defined - Topic_Details, Keyword_topic, Topic_section, Topic_class, Section_course, which join the respective entities.

The relational tables obtained after the transformation of the entity-relationships diagram into the relational model are structured in such a way that allows a future development of the database - creation of new tables and/or attributes for storing additional information such as data of creation and/or updating, language of each topic, etc.

The database is implemented by means of the database management system Microsoft Access $(14,15)$. The database structure is defined to ensure the performance of the most frequently performed operations - data inserting, updating, and searching. 
GEORGIEVA-TRIFONOVA T., et al.

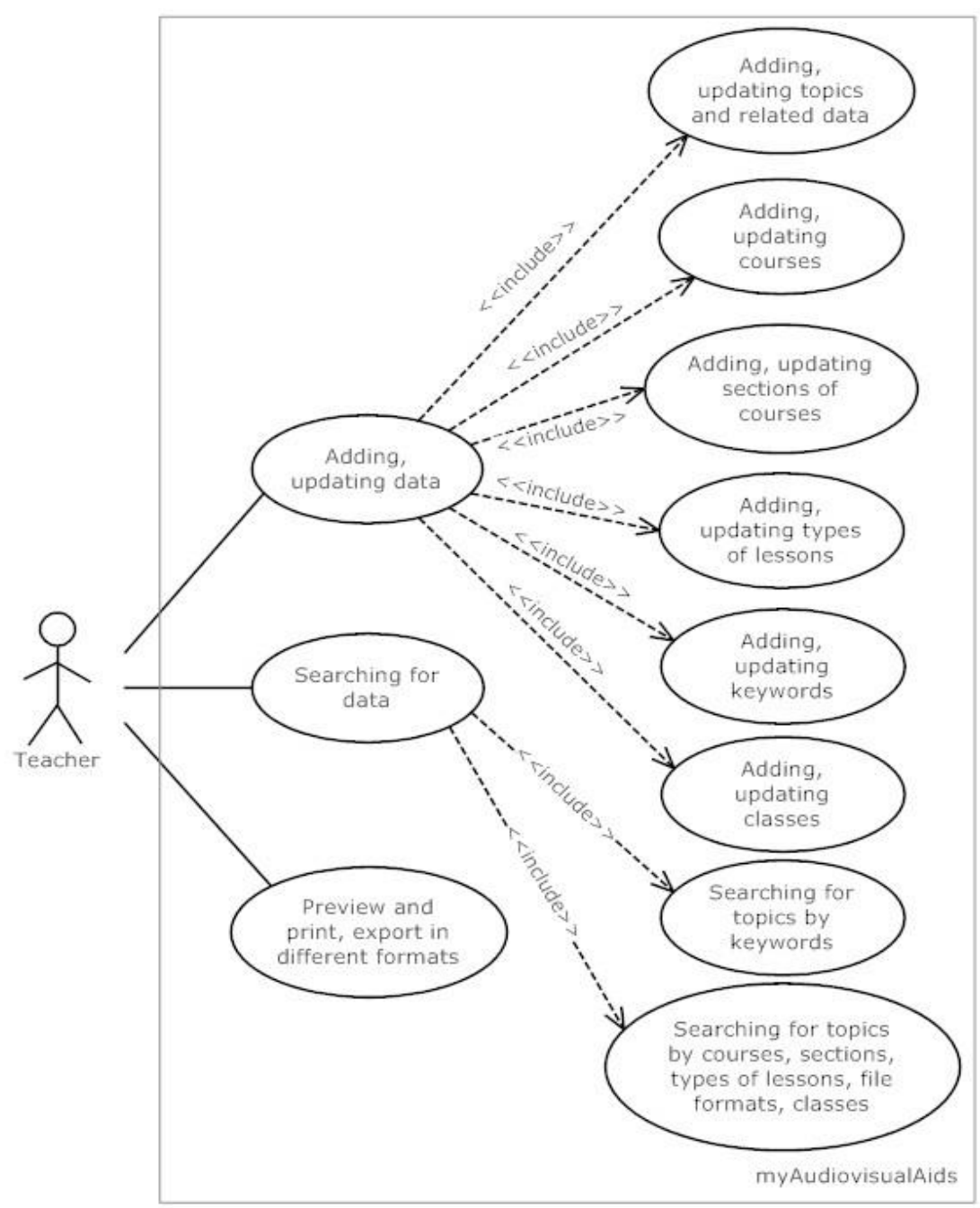

Figure 1. UML use case diagram

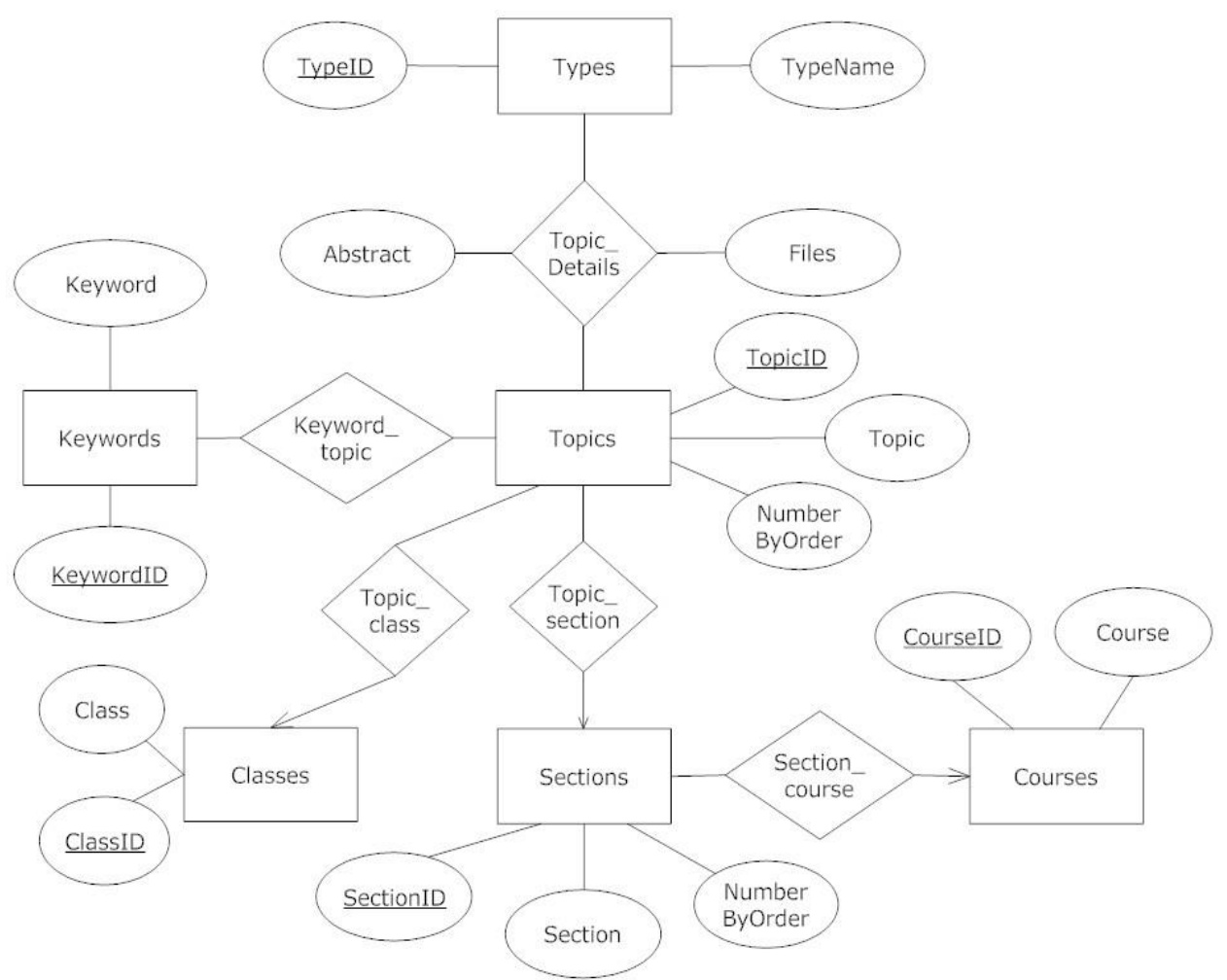

Figure 2. Entity-relationships diagram 
In accordance with the predetermined requirements, the interface of the implemented application proposes the following main functionality:

- Data inserting, browsing, updating, deleting;

The application myAudiovisualAids allows inserting, updating, deleting digital didactic aids on topics; selecting types of the lessons (new knowledge, exercises, verification and assessment of knowledge, etc.), classes, courses, sections, keywords from combo boxes; storing files that contain the audiovisual aids themselves by attaching
GEORGIEVA-TRIFONOVA T., et al. one or more files, electronic versions of didactic aids.

As a result, the implemented information system can be considered as a mobile electronic library because it can easily be moved and copied - it is only one file.

- Data searching.

The information system myAudiovisualAids possesses an advanced search function for audiovisual aids in the database. These aids can be searched by one or more keywords as well as a course, a section, a lesson type, a file format and/or a class.

The form for the second type of searching is shown in Figure 3.

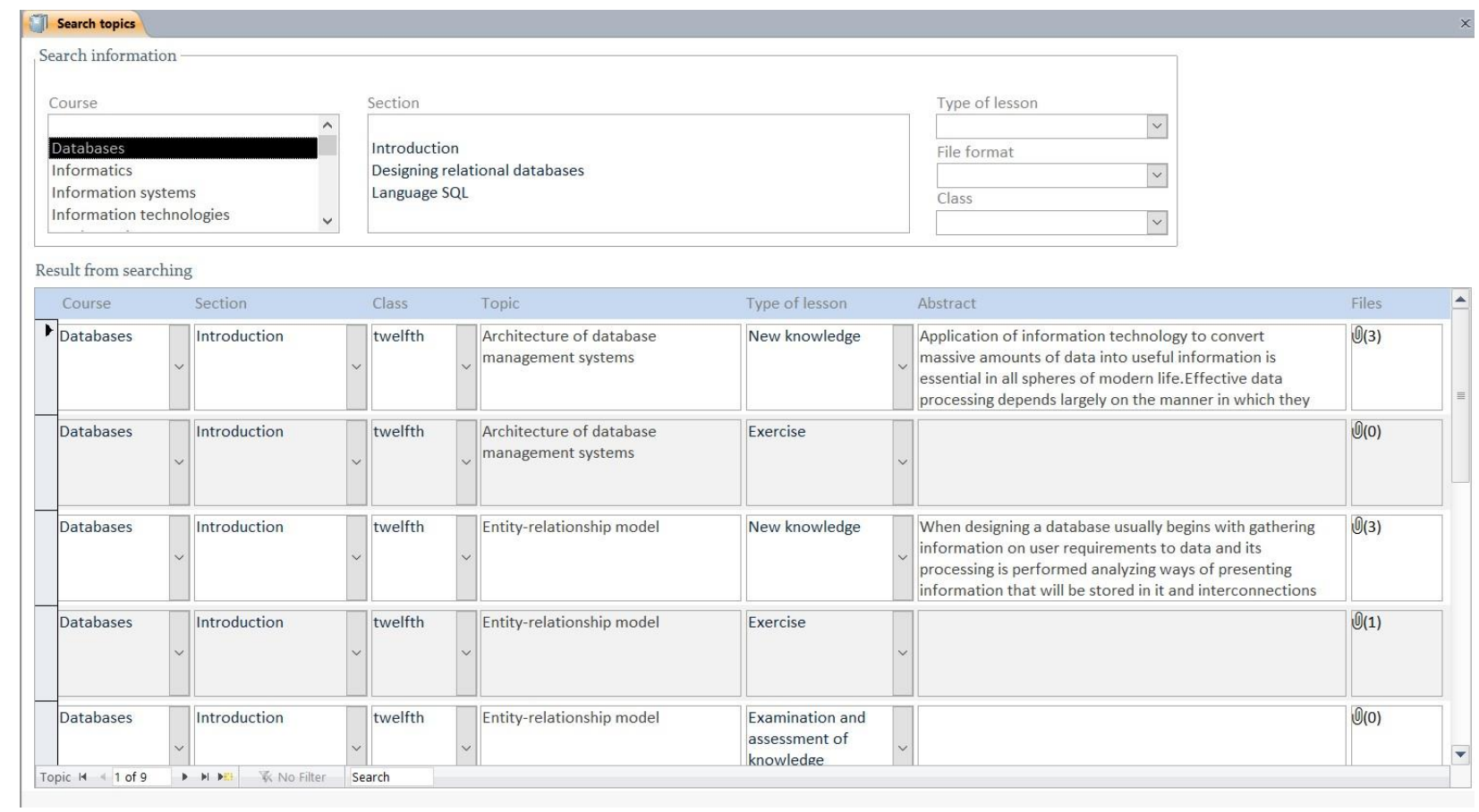

Figure 3. Form for searching by course, section, type of lesson, file format and/or class

The program provides an additional possibility for pre-viewing and printing, as well as exporting to a TXT, RTF, HTML, XML file of a list of selected topics.

The implemented program is available free of charge (under Creative Commons license) after submitting a request for receiving on authors email addresses. It can be provided in two variants:

- Installation program;

This variant of myAudiovisualAids does not require a previously installation of Microsoft Access. The created installation program of myAudiovisualAids installs Access Runtime, which is free and is enough to start and work with the information system.

- File in ACCDB format.
This variant requires a previously installation of Microsoft Access, version 2007 or later. The advantage of this variant is the possibility for implementing additional functionalities and / or modifying the application according to specific user requirements and needs.

\section{CONCLUSION}

All things put into perspective; we can say that in our global world information technology is changing with an unprecedented speed. Technology takes part in literally every sphere of our life and using it in education is not only a matter of choice, but a necessity. The suggested information system facilitates and enhances teacher's work, creating a collection of the audiovisual aids, which helps to easily find the needed resource, as well as to update, share, analyze and plan every digital material. 
The effective use of the data and information stored in the information system will assist the contemporary teacher in making decisions in his daily praxis.

\section{REFERENCES}

1. Jahnke, I., Digital didactical designs: teaching and learning in CrossActionSpaces. Routledge, New York, 2016.

2. Rasul, S., Bukhsh, Q., Batoolc, S., A study to analyze the effectiveness of audio visual aids in teaching learning process at university level, Procedia - Social and Behavioral Sciences, 28:78-81, 2011.

3. Encyclopedia Britannica, Audiovisual education, available at: https://www.britannica.com/topic/audiovisu al-education, 1998 (accessed 9 July 2018).

4. Ciara, K., The Benefits of Using AudioVisual Aids in Teaching, available at: http://www.techprevue.com/audio-visualaids-benefits-teaching, 2016 (accessed 9 July 2018).

5. Barani, G. et al., The effect of application of picture into picture audio- visual aids on vocabulary learning of young Iranian ELF learners, Procedia Social and Behavioral Sciences, 2:5362-5369, 2010.

6. Suduc, A.-M. et al., Information and communication technologies in science education, Procedia Social and Behavioral Sciences, 15:1076-1080, 2011.
GEORGIEVA-TRIFONOVA T., et al.

7. Cavus, N., Distance Learning and Learning Management Systems, Procedia - Social and Behavioral Sciences, 19:87 -877, 2015.

8. Ingwersen, H., A Comparison of the 4 Biggest Corporate LMSs: Which is Right for Your Business?, available at: https://blog.capterra.com/comparison-4biggest-corporate-lmss-right-business, 2017 (accessed 9 July 2018).

9. Fenton, W., The Best LMS (Learning Management Systems) of 2017, available at:

https://www.pcmag.com/article2/0,2817,24 88347,00.asp, 2017 (accessed 9 July 2018).

10.Kats, Y., Learning Management Systems and Instructional Design: Best Practices in Online Education, IGI Publishing Hershey, PA, USA, 2013.

11.Crawford, R., Managing information technology in secondary schools, Routledge, New York, 2003.

12.Betcher, C., Lee, M., The interactive whiteboard revolution: teaching with IWBs, ACER Press, Victoria, Australia, 2009

13.Chen, P., The Entity-Relationship Model: Toward a Unified View of Data, $A C M$ Transactions on Database Systems, 1(1):936, 1976.

14.Groh, M. R., Access 2010 Bible, Wiley Publishing, Inc. 2010.

15.Hennig, T., Cooper, R., Griffith, G. L., Dennison, J., Access 2010 VBA Programmer's Reference. Wiley Publishing, Inc., 2010. 